\title{
Lock-in amplifier with a high common-mode rejection ratio in the range of 0.02 to $100 \mathrm{kHz}$
}

\author{
Pavel Baranov ${ }^{1}$, Valeriy Borikovํㅜ, Veronica Ivanova ${ }^{1}$, Bien Bui Duc ${ }^{1}$, Sergey Uchaikin², Cheng-Yang Liu ${ }^{3}$ \\ ${ }^{1}$ Division for Electronic Engineering, National Research Tomsk Polytechnic University, 30 Lenin Avenue, 634050 Tomsk, Russia \\ 2 IBS Center for Axion and Precision Physics Research., KAIST Munji Campus, 193 Munji-ro, Yuseong-gu, Daejeon 34051, South Korea \\ ${ }^{3}$ Department of Biomedical Engineering, Tamkang University, No. 151, Yingzhuan Road, Tamsui District, New Taipei City, Taiwan
}

\section{ABSTRACT}

The paper presents a new lock-in amplifier with a differential input. The lock-in amplifier has a high common-mode rejection ratio of $200 \mathrm{~dB}$ at $1 \mathrm{kHz}$ and $160 \mathrm{~dB}$ in the frequency range of $20 \mathrm{~Hz}$ to $100 \mathrm{kHz}$. A method for extending the dynamic range of comparing signals is suggested. The experimental results of metrological characteristic tests are discussed.

\section{Section: RESEARCH PAPER}

Keywords: lock-in amplifier; differential input; voltage dividers; common-mode rejection ratio; calibration

Citation: Pavel Baranov, Valeriy Borikov, Veronica Ivanova, Bien Bui Duc, Sergey Uchaikin, Cheng-Yang Liu, Lock-in amplifier with a high common-mode rejection ratio in the range of 0.02 to $100 \mathrm{kHz}$, Acta IMEKO, vol. 8, no. 1, article 14, March 2019, identifier: IMEKO-ACTA-08 (2019)-01-14

Section Editor: Alexandru Salceanu, Technical University of lasi, lasi, Romania

Received October 03, 2018; In final form February 19, 2019; Published March 2019

Copyright: @ 2019 IMEKO. This is an open-access article distributed under the terms of the Creative Commons Attribution 3.0 License, which permits unrestricted use, distribution, and reproduction in any medium, provided the original author and source are credited.

Funding: The research was carried out at Tomsk Polytechnic University within the framework of Tomsk Polytechnic University Competitiveness Enhancement Program grant \# VIU-INK 76/2017 and funded by Russian Science Foundation (RSF), Project \# 17-79-10083.

Corresponding author: Pavel Baranov, e-mail: bpf@tpu.ru

\section{INTRODUCTION}

One of the classic problems of instrumentation is the comparison of alternating voltage amplitudes [1]-[4]. Inductive voltage dividers (IVDs) are usually used for precision AC [5] [11]ratio measurements. To calibrate IVD ratio $K_{I V D}$ errors, the calibrated IVD referencing method is the most widely used [12], [13]. For example, this method is used in the National Institute of Standards and Technology (NIST, USA) to calibrate decade IVDs $(54120 \mathrm{C}-54131 \mathrm{C}$ services) in the range of $50 \mathrm{~Hz}$ to $20000 \mathrm{~Hz}$ [14]. In the calibration process, an IVD ratio is compared with a ratio from a reference IVD using the differential method of measurement. Comparisons of two AC voltages $v_{x}(t)$ and $\nu_{0}(t)$ with the same frequency $\omega$ lock-in

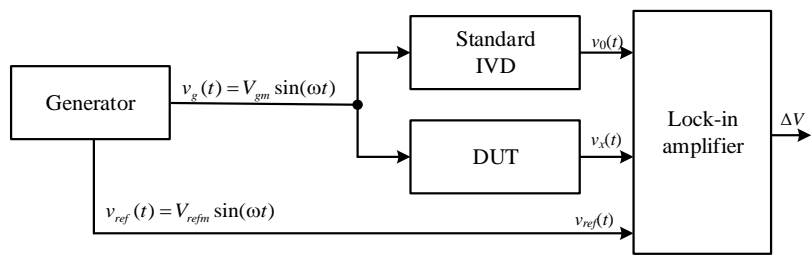

Figure 1. Block diagram of a measuring IVD ratio error system. amplifiers with a differential input (LIADI) are usually applied. [15], [16]. LIADI defines the measurement precision and permits the separation of a low differential signal from a high common-mode interfering signal.

A block diagram of a measuring IVD ratio error using the LIADI system is shown in Figure 1.

Figure 2 shows a block diagram of a simple LIADI. According to the scheme, the amplitudes of in-phase signals $v_{x}(t)$ and $v_{0}(t)$ are compared, the signal is then amplified and the signal difference detected.

Lock-in amplifiers are mainly used in physical and chemical sensing applications [17]-[26]. However, LIADI inputs are also used for calibration measurement instruments [15], [16], [27].

Equation (1) below defines the output voltage of simple LIADI (Figure 2):

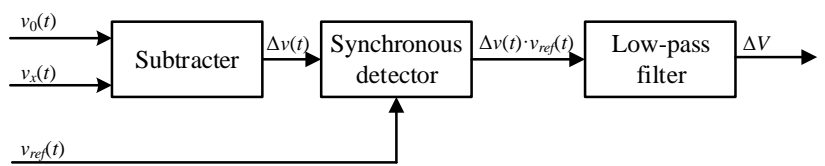

Figure 2. A simple lock-in amplifier with a differential input (a basic LIADI). 


$$
\begin{gathered}
\Delta V \approx \frac{1}{U}\left(\frac{1}{2 \pi} \int_{0}^{\infty}\left[v_{x}(t)-v_{0}(t)+\frac{v_{x}(t)+v_{0}(t)}{2 C M R R}\right] v_{r e f}(t) d t\right) \\
v_{x}(t)=V_{x m} \sin \left(\omega t+\varphi_{x}\right) \\
v_{0}(t)=V_{0 m} \sin \left(\omega t+\varphi_{0}\right) \\
v_{r e f}(t)=V_{r e f m} \sin \left(\omega t+\varphi_{r e f}\right)
\end{gathered}
$$

where $U$ is the multiplier denominator voltage, $V ; V_{0 \mathrm{~m}}$ and $V_{\mathrm{xm}}$ are the compared signals amplitudes, $V ; V_{r e f m}$ is the reference voltage; $V ; \varphi_{0}, \varphi_{x}$, are the compared signal phases, $\operatorname{rad} ; \varphi_{r f}$ is the reference signal phase, rad; and CMRR is the common-mode rejection ratio.

As shown in equation (1), the signal amplitude difference $\Delta V$ has an error that depends on the phase shifts of the input signals $\varphi_{x}$, and $\varphi_{0}$ is a common-mode rejection ratio and phase shift of reference signal $\varphi_{r e f}$.

[16] and [27] explain the possibility of reducing the error of measuring the absolute difference between the compared voltages induced by a phase error.

In this current work, methods of reducing the errorconditioned measurements by using the finite value of the common-mode rejection ratio in a LIADI are suggested. A new circuit is proposed for the input stage of the LIADI input based on an instrumentation amplifier and a voltage follower.

\section{THE COMMON-MODE REJECTION RATIO FOR IVDS}

Requirements for the common-mode rejection ratio can be improved, specifically when the verification and calibration of the IVD at a $1-10 \mathrm{nV}$ maximum resolution of the lock-in amplifier within the medium frequency range at the upper level of $10 \sqrt{2} \mathrm{~V}$ of the compared voltage dynamic range [28]-[30].

The instrumentation amplifier application is the standard method for input differential signal extraction.

The output voltage is determined by equation (2) because its response delay can be neglected in frequency range

$V_{\text {out }}=A_{\mathrm{d}} V_{\mathrm{d}}+A_{\mathrm{c}} V_{\mathrm{c}}=A_{\mathrm{d}}\left(V_{\mathrm{d}}+\frac{V_{\mathrm{c}}}{C M R R}\right)$,

where $A_{\mathrm{d}}$ is the differential-mode gain; $A_{\mathrm{c}}$ is the commonmode gain; $V_{\mathrm{d}}$ is the differential voltage, $V$; and $V_{\mathrm{c}}$ is the common-mode voltage, $V$.

The finite value of CMRR is determined by the value of relative error $\gamma c$. In this case, the ultimate requirements for CMRR are

$$
C M R R=\frac{V_{\mathrm{c}}}{\gamma_{\mathrm{c}} V_{\mathrm{d}}} .
$$

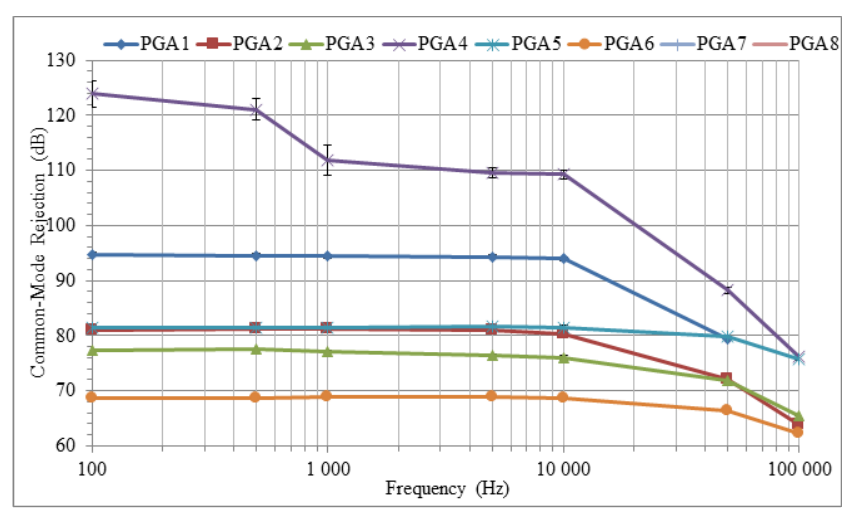

Figure 3. Results of experimental studies concerning the PGA207 instrumentation amplifier.
According to equation (3), the common-mode rejection is (200-220) dB at $\gamma_{c}=0.1$, but it is not realised in commercially available lock-in amplifiers. Other important characteristics of a lock-in amplifier that must be taken into account are the bandwidth, high input impedance at measurement inputs, high stability, and low nonlinearity of the differential signal gain.

For example, one of the best commercially available lock-in amplifiers, SR830 of Stanford Research Systems, has a common-mode rejection of $100 \mathrm{~dB}$ up to $10 \mathrm{kHz}$, decreasing by $6 \mathrm{~dB}$ per octave above $10 \mathrm{kHz}$, and an input impedance $10 \mathrm{MOhm} / / 25 \mathrm{pF}$ [31]. In [32], a special guarded vector voltmeter (a lock-in amplifier) with a bootstrapping-guarding technique [33] is proposed for the calibration of the IVD. It has a high common-mode rejection of $180 \mathrm{~dB}$ at $1 \mathrm{kHz}$. With our IVD [28], we must compare voltages of up to $10 \cdot \sqrt{ } 2 \mathrm{~V}$ with a resolution of up to $10 \mathrm{nV}$ at a frequency of $1 \mathrm{kHz}$. Therefore, by means of the lock-in amplifier, a common-mode rejection of about $200 \mathrm{~dB}$ should be obtained.

We suggest the use of the instrumentation amplifier in its integrated form with a programmable gain ratio for IVD comparison. In such amplifiers, CMRR does not depend on the output impedance of the compared signal sources because its dependence on the internal impedances of the cascaded instrumentation amplifier is technologically minimised. After analysing the parameters of the different instrumentation amplifiers performed for the differential signal extraction, Texas Instrument PGA207 has been chosen [34].

However, PGA207 and similar amplifiers have a low common-mode rejection of $100 \mathrm{~dB}$ at $A_{\mathrm{d}}=10$. Experimental studies of $C M R R$ on eight PGA207 samples were carried out. Equal values of voltage $(5 \mathrm{~V})$ were applied to both the PGA207 inputs, and the value of voltage $\Delta V$ by the lock-in amplifier SR830 was measured on the PGA207 output at $A_{\mathrm{d}}=10$.

All tests were undertaken three times for each frequency at an environment temperature of $22 \pm 2{ }^{\circ} \mathrm{C}$. The common-mode signal rejection ratio was calculated by

$C M R R=20 \lg \frac{5}{\Delta V}$,

The results of the experimental studies (Figure 3) of the PGA207 instrumentation amplifier have confirmed the low value of the common-mode rejection ratio and have shown significant dispersion of the common-mode rejection ratio from sample to sample.

In summary, it has been shown, both theoretically and empirically, that the circuit technique must be used for further increasing the common-mode rejection.

\section{APPLICATION OF TRACKING POWER SUPPLY TO DIFFERENTIAL SIGNAL EXTRACTION}

The common-mode rejection in lock-in amplifiers can be increased by the addition of the voltage follower to the scheme, as shown in Figure 4, which provides the tracking power supply of the instrumentation amplifier.

The efficient common-mode rejection ratio is

$C M R R_{\mathrm{ef}}(t)=\frac{C M R R(t)}{1-A_{\mathrm{f}}(t)}$,

where $A_{\mathrm{f}}(t)$ is the voltage follower voltage gain.

The common-mode rejection decrease to $160-180 \mathrm{~dB}$ can be achieved within the frequency range of practically inertialess 


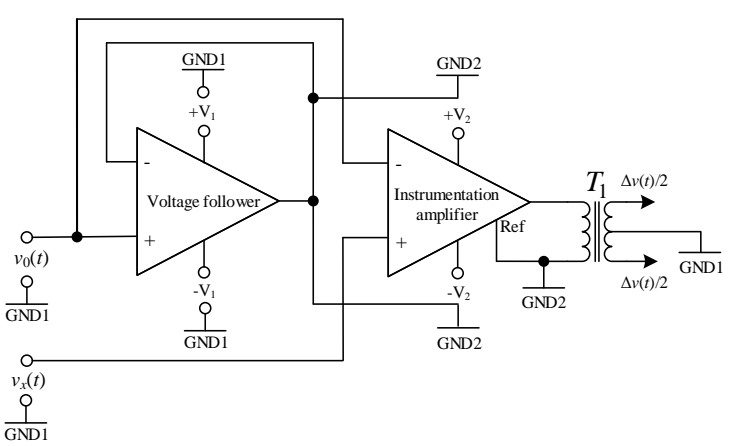

Figure 4. Differential signal extraction scheme.

circuits at easily reachable values of 0.999-0.9999 of the voltage follower voltage gain.

This approach has serious disadvantages. The transmission factor module of the voltage follower and the instrumentation amplifier decreases with the increase in frequency, resulting in the CMRR of the whole circuit [35].

Thus, we can see the high rejection of the common-mode signal only in the narrow frequency band.

Tracking a power supply circuit with the use of a voltage follower also provides an increase in the input impedance of the measuring channels in the wide frequency range, especially the $v_{x}$ channel of the instrumentation amplifier.

Figure 5 shows the novel technical implementation of the input stage of the lock-in amplifier that is used for tracking the symmetrical power supply of the instrumentation amplifier. The connection circuit of the instrumentation amplifier is presented in Figure 6.

The high-quality operating amplifier $\left(D A_{1}\right)$ in the voltage follower circuit, as shown in Figure 5, must be used to solve the posed problem.

This amplifier is provided with an acceptable voltage profile of no less than $\pm 18 \mathrm{~V}$ of the tracking symmetrical power supply and is presented by OP285. A conventional representation (Figure 5) of the uncomplemented input supply of this amplifier is conditioned by means of the flexible diode protection circuit of the voltage follower inputs in a number of cases so as to provide its normal quiescent mode at the disconnection of a signal source.

The effect of cable capacitance is reduced due to the suspension of their braiding to the voltage follower input (Figure 6).

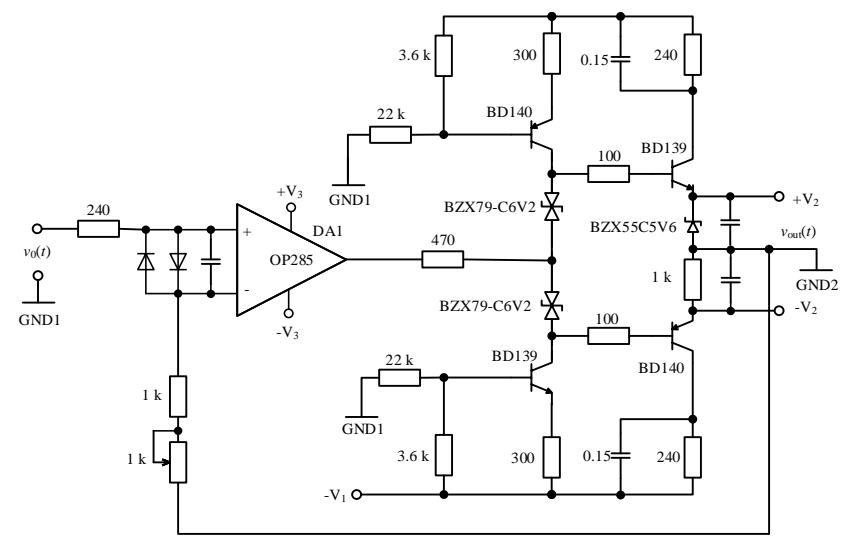

Figure 5. Voltage follower circuit for tracking power supply formation.

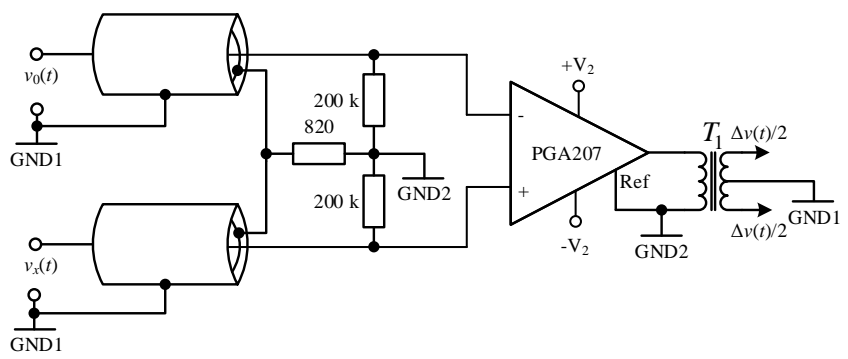

Figure 6. Connection circuit of the instrumentation amplifier.

As shown in Figure 6, the output signal is to be obtained relative to the original ground. It can be carried out, at least, by using optical or transformer isolation. The first method leads to an abrupt loss of sensitivity due to the properties of diode optrons. Therefore, the second method is more expedient.

\section{INVESTIGATION OF THE DIFFERENTIAL SIGNAL EXTRACTION CIRCUIT}

The differential signal extraction circuit (see Figure 5 and Figure 6) was simulated in the Multisim software, applying common-mode input signals with amplitudes $V_{0 \mathrm{~m}}=V_{x \mathrm{~m}}=$ $10 \cdot \sqrt{2} \mathrm{~V}$. The frequency dependences of the $C M R R$ from $\left|A_{\mathrm{f}}(t)\right|$, phase $A_{\mathrm{f}}(t)$, and output voltage amplitude $|\Delta v(t)|$ were estimated. The results of the simulation are shown in Table 1.

The proposed circuit permits increasing the common-mode rejection up to 141 to $220 \mathrm{~dB}$ at a frequency range of up to 100 $\mathrm{kHz}$ (see Table 1).

The obtained resolution is $<1 \mathrm{nV}$ in the frequency range of up to $10 \mathrm{kHz},<10 \mathrm{nV}$ in the frequency range of up to $20 \mathrm{kHz}$, $<100 \mathrm{nV}$ in the frequency range of up to $60 \mathrm{kHz}$, and $<1000 \mathrm{nV}$ in the frequency range of up to $100 \mathrm{kHz}$.

The differential signal extraction circuit implementation is shown in Figure 7. The experimental investigation setup for the differential signal extraction circuit is shown in Figure 8.

The $\mathrm{CH} 0$ output of the Fluke 5520A calibrator supplied a voltage of $10 \cdot \sqrt{ } 2 \mathrm{~V}$ and a frequency of $1 \mathrm{kHz}$. The same signal was applied to the DI-3m [28] inductive divider with a ratio of 0.100000 . The $\Delta V$ values were measured at the lock-in amplifier SR830 resolution up to $2 \mathrm{nV}$, five times for 35 different frequencies (Figure 8).

Table 1. Results of the differential signal extraction circuit simulation.

\begin{tabular}{rcccc}
\hline Frequency $(\mathrm{Hz})$ & $\left|A_{\mathrm{f}}(t)\right|$ & $\begin{array}{c}\text { Phase of } \\
\left|A_{\mathrm{f}}(t)\right|(\mathrm{deg})\end{array}$ & $|\Delta v(t)|(\mathrm{V})$ & $\mathrm{CMR}(\mathrm{dB})$ \\
\hline 100 & 1.000001 & $-0.84 \cdot 10^{-6}$ & $1.01 \cdot 10^{-10}$ & 220 \\
1000 & 1.000002 & $-8.67 \cdot 10^{-6}$ & $2.01 \cdot 10^{-10}$ & 214 \\
10000 & 1.000003 & $-83.1 \cdot 10^{-6}$ & $1.01 \cdot 10^{-9}$ & 200 \\
20000 & 1.000010 & $-161 \cdot 10^{-6}$ & $6.57 \cdot 10^{-9}$ & 184 \\
30000 & 1.000021 & $-201 \cdot 10^{-6}$ & $1.91 \cdot 10^{-8}$ & 174 \\
40000 & 1.000037 & $-137 \cdot 10^{-6}$ & $4.11 \cdot 10^{-8}$ & 168 \\
50000 & 1.000048 & $112 \cdot 10^{-6}$ & $6.97 \cdot 10^{-8}$ & 163 \\
60000 & 1.000062 & $783 \cdot 10^{-6}$ & $1.05 \cdot 10^{-7}$ & 160 \\
70000 & 1.000065 & $1.84 \cdot 10^{-3}$ & $1.44 \cdot 10^{-7}$ & 157 \\
80000 & 1.000058 & $3.79 \cdot 10^{-3}$ & $2.07 \cdot 10^{-7}$ & 157 \\
90000 & 1.000040 & $6.42 \cdot 10^{-3}$ & $4.85 \cdot 10^{-7}$ & 146 \\
100000 & 1.000016 & $11.5 \cdot 10^{-3}$ & $8.89 \cdot 10^{-7}$ & 141 \\
\hline
\end{tabular}




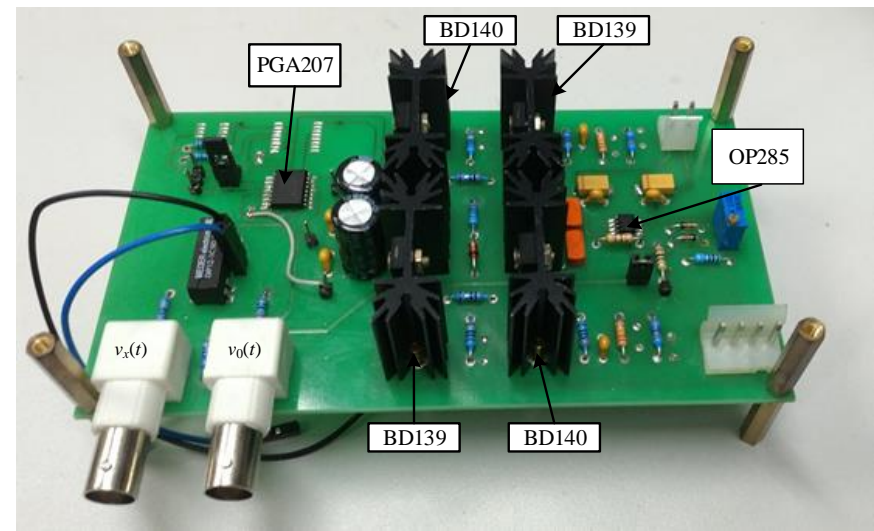

Figure 7. A photo of the differential signal extraction circuit implementation.

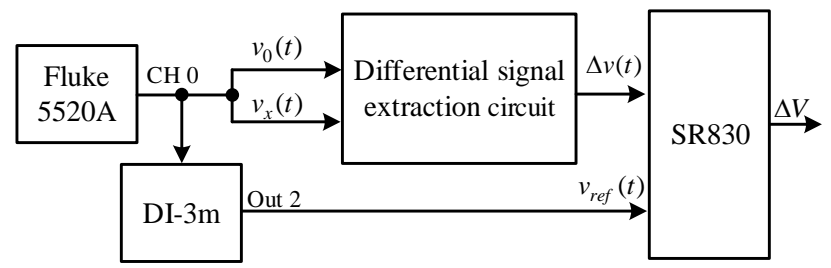

Figure 8. Experimental investigation setup.

The common-mode rejection of the differential signal extraction circuit is calculated as

$$
C M R R=20 \lg \frac{10 \sqrt{2}}{\Delta V},
$$

where $10 \sqrt{ } 2$ is calibrator Fluke $5520 \mathrm{~A}$ nominal voltage, $V$.

Figure 9 shows the implementation of the differential signal extraction scheme that allows us to increase the common-mode rejection up to 100 to $190 \mathrm{~dB}$ at a frequency range of up to 100 $\mathrm{kHz}$. The obtained maximum resolution is $<10 \mathrm{nV}$ in the frequency range of up to $1 \mathrm{kHz}$.

The sample and hold circuit can be added to the lock-in amplifier for achieving the required common-mode rejection. One of the technical realisations of the sample and hold circuit for the lock-in amplifier us described in [35]. Experimental investigations for differential signal extraction circuit with sample and hold circuit [35] are also provided by the scheme shown in Figure 8. The results of the differential signal extraction circuit experimental investigation with sample and hold circuit are shown in Figure 10.

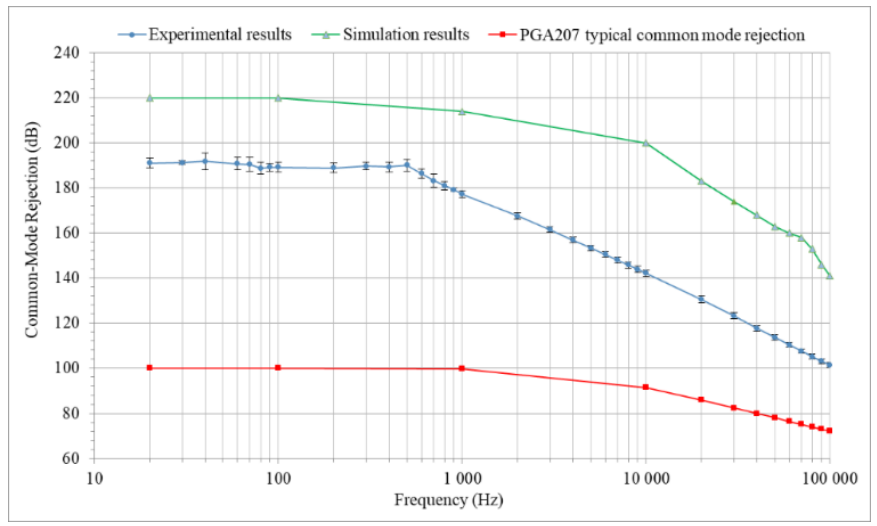

Figure 9. Results of the differential signal extraction circuit experimental investigation.

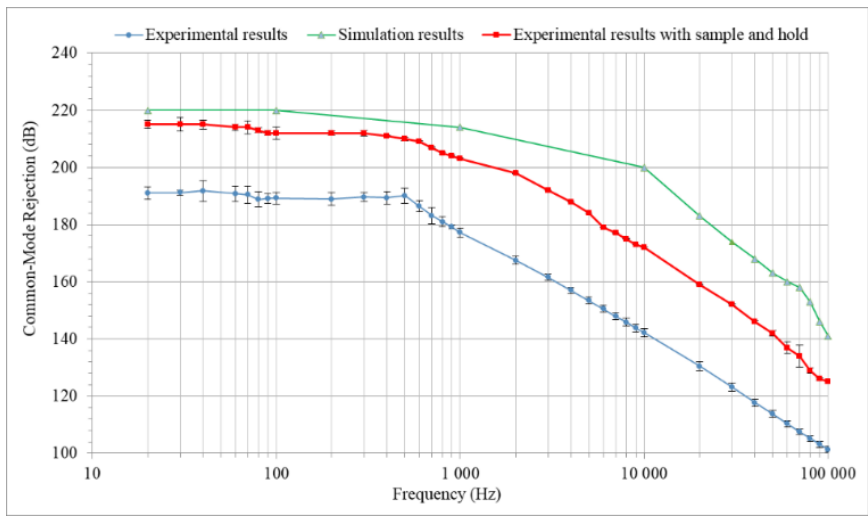

Figure 10. Results of the differential signal extraction circuit experimental investigation with sample and hold circuit.

Figure 10 shows the implementation of a differential signal extraction circuit with sample and hold circuit, which allows us to increase the common-mode rejection up to 125 to $215 \mathrm{~dB}$ in a frequency range of up to $100 \mathrm{kHz}$. The obtained maximum resolution is $<1 \mathrm{nV}$ in the frequency range of up to $1 \mathrm{kHz}$ and $<10000 \mathrm{nV}$ in the frequency range of up to $100 \mathrm{kHz}$.

\section{NEW LIADI}

\subsection{Block schematic}

The new LIADI structure, which uses a developed differential signal extraction circuit with sample and hold circuit, is introduced. A block diagram of the new LIADI is shown in Figure 11.

The LIADI consists of a voltage follower (VF); an instrumentation amplifier (IA); a programmable gain amplifier (PGA), a synchronous detector (SD); a low-pass filter (LPF); a sample and hold device (SH); an analogue-to-digital converter (ADC); and a microcontroller (MC).

The VF is assembled on the OP285 and PGA207 ICs; the PGA207 also accommodates IA, PGA, and SH. The synchronous detector is based on the AD734 IC, and its denominator voltage is set close to $1 \mathrm{~V}$ for improved sensitivity [36]. The LPF has a cut-off frequency of $0.2 \mathrm{~Hz}$ and is based on the OP270 IC. To achieve a uniform transient response, we use a third-order Bessel filter.

The LIADI can automatically be calibrated to reduce the effect of a residual in-phase component on the LPF output. To calibrate, the same voltage $v_{0}(t)$ is applied on both the inputs of the differential signal extraction scheme (Figure 4). The output voltage is stored in the $\mathrm{SH}$ and serves as a correction during measurements.

The ADC is assembled on the MAX110 IC. An MC (ATmega128) controls the operation of the LIADI's PGA, implements an additional digital filter, and indicates the measurement results.

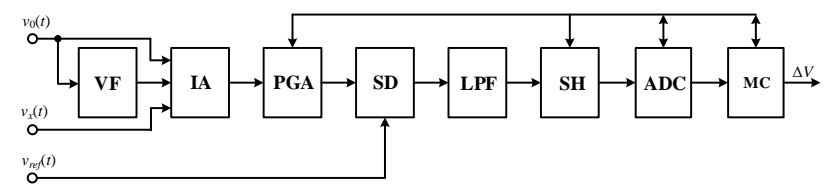

Figure 11. New LIADI block diagram. 


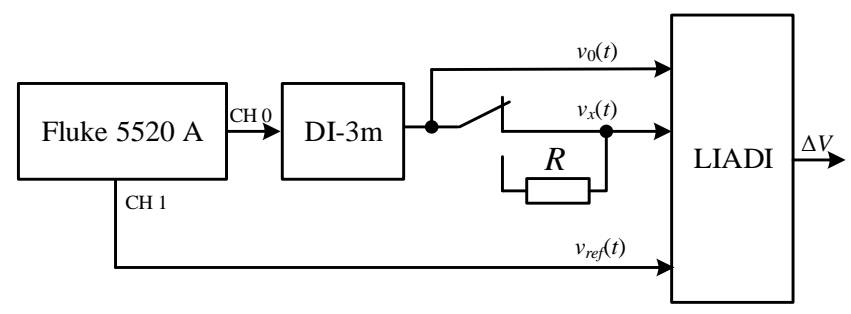

Figure 12. Diagram of the setup to measure the $V_{x}$ channel input resistance of the LIADI.

Table 2. Calculation data on input resistances.

\begin{tabular}{lcc}
\hline Resistor $\boldsymbol{R}$ & Indicator reading, $(\boldsymbol{\mu V})$ & Input resistance, $(\mathrm{M} \Omega)$ \\
\hline In circuit $V_{0}$ & 5 & 200 \\
In circuit $V_{x}$ & -0.5 & 2000 \\
\hline
\end{tabular}

\subsection{LIADI input resistance}

The characteristics of the LIADI are measured experimentally using the DI-3m [28] reference divider. The DI$3 \mathrm{~m}$ has auxiliary and main outputs connected to the output of the first decade (Out.1) and the minor decade (Out.2).

A $V_{x}$ channel input resistance was determined using the Fluke 5520 A calibrator with a two-step indirect measurement method (Figure 12). The calibrator's main (CH0) and auxiliary (CH1) outputs supplied the $1 \mathrm{kHz}$ sinusoidal voltage of $10 \sqrt{2} \mathrm{~V}$ and $5 \sqrt{2} \mathrm{~V}$, respectively. The ratio $K_{I V D}$ of the DI-3m was set to 0.100000 .

First, the same signal was applied to the $V_{0}$ and $V_{x}$ inputs to calibrate the LIADI. Second, the input $V_{x}$ was connected via a precision reference resistance $R$ of $1 \mathrm{k} \Omega$ (USF340 1.00K $0.01 \%$ $5 \mathrm{ppm} /{ }^{\circ} \mathrm{C}$ [37]), and the voltage difference $\Delta V$ was recorded according to the data provided by the LIADI indicator.

The LIADI input resistance was calculated according to

$R_{I N}=\frac{V_{I N} K_{I V D}}{|\Delta V| / R}$

where $V_{I N}$ is the calibrator output voltage $\mathrm{CH} 0, V$.

The $V_{0}$ channel-based input resistance was determined in a similar way, connecting the input $V_{0}$ via reference resistor $R$. The difference in voltages $\Delta V$ was recorded.

The calculated input resistances are given in Table 2 .

\subsection{The LIADI resolution}

The LIADI resolution was determined according to the scheme shown in Figure 13.

To measure the LIADI resolution, the indirect measurement method was used. The IVD DI-3m working calibration standard was used to set up nominal voltage $V_{D I 3 m}$ between outputs 1 and 2 . The voltage difference $\Delta V$ was recorded according to the data provided by the LIADI indicator.

The $\mathrm{CHO}$ and $\mathrm{CH} 1$ outputs of the calibrator supplied

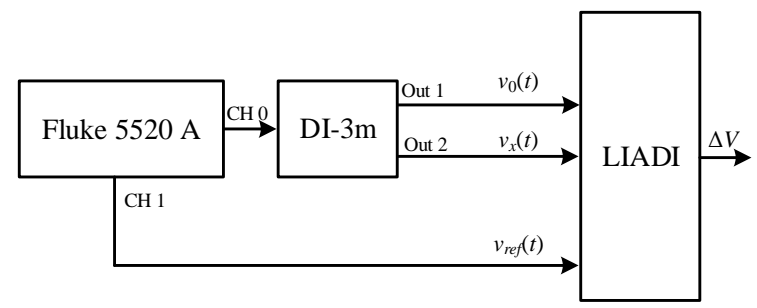

Figure 13. Diagram of the setup for resolution measurement.
Table 3. LIADI resolution.

\begin{tabular}{|c|c|c|}
\hline $\begin{array}{l}\text { Out-of-balance voltage } \\
\qquad \text { in } \mu v\end{array}$ & LIADI output $\Delta U$ in $\mu \mathrm{V}$ & $\begin{array}{l}\text { Relative reading } \\
\text { deviation } \gamma \text { in \% }\end{array}$ \\
\hline \multicolumn{3}{|c|}{ LIADI resolution of $10 \mu \mathrm{V}$} \\
\hline 100 & 100 & $<0.5$ \\
\hline 200 & 200 & $<0.3$ \\
\hline 300 & 300 & $<0.2$ \\
\hline 400 & 400 & $<0.2$ \\
\hline 500 & 500 & $<0.1$ \\
\hline \multicolumn{3}{|c|}{ LIADI resolution of $1 \mu \mathrm{V}$} \\
\hline 10 & 10 & $<5.0$ \\
\hline 20 & 20 & $<2.5$ \\
\hline 30 & 30 & $<1.7$ \\
\hline 40 & 40 & $<1.3$ \\
\hline 50 & 50 & $<1.0$ \\
\hline \multicolumn{3}{|c|}{ LIADI resolution of $100 \mathrm{nV}$} \\
\hline 10 & 10.1 & 1.0 \\
\hline 20 & 20.4 & 2.0 \\
\hline 30 & 30.7 & 2.3 \\
\hline 40 & 41 & 2.5 \\
\hline 50 & 51.2 & 2.4 \\
\hline \multicolumn{3}{|c|}{ LIADI resolution of $10 \mathrm{nV}$} \\
\hline 10 & 10.21 & 2.1 \\
\hline 20 & 20.34 & 1.7 \\
\hline 30 & overload & - \\
\hline
\end{tabular}

voltages of $10 \sqrt{2} \mathrm{~V}$ and $5 \sqrt{2} \mathrm{~V}$, respectively, with a frequency of $1 \mathrm{kHz}$. The DI-3m ratio of output 1 was set to 0.100000 . To determine resolutions $10 \mathrm{nV}, 100 \mathrm{nV}$, and $1 \mu \mathrm{V}$, the IVD ratio of output 2 was varied in the range of 0.100001 to 0.100005 . To determine resolution $10 \mu \mathrm{V}$, the IVD ratio of output 2 was varied in the range of 0.100010 to 0.100050 . The LIADI relative deviation was calculated according to

$\gamma=\frac{\left(V_{D I 3 m}-\Delta V\right)}{V_{D I 3 m}} \cdot 100$

where $V_{D I 3 m}$ is the IVD DI-3m nominal voltage between outputs 1 and 2, $V$. The results of the measurements are presented in Table 3.

\subsection{LIADI dynamic range}

The dynamic range of the compared voltages was defined according to the scheme shown in Figure 13. Again, the $\mathrm{CH} 0$ and $\mathrm{CH} 1$ outputs of the calibrator supplied voltages of $10 \sqrt{2} \mathrm{~V}$ and $5 \sqrt{2}$, respectively, with a frequency of $1 \mathrm{kHz}$. The DI- $3 \mathrm{~m}$ ratio of output 1 was set to 0.999999 . The IVD ratio of output 2 was varied in the range of 0.999998 to $0.999994 . \Delta V$ values were measured at the LIADI resolution of $100 \mathrm{nV}$. The LIADI relative deviation was calculated according to equation (8).

The minimum amplitude of the compared voltages was determined with similar calibrator settings. The DI-3m ratio of output 1 was set to 0.000000 . The IVD ratio of output 2 was varied in the range of 0.000001 to $0.000005 . \Delta V$ values were measured at the LIADI resolution of $100 \mathrm{nV}$. Again, the LIADI relative deviation was calculated according to equation (8).

The results of the measurements are presented in Table 4. 
Table 4. Maximum and minimum amplitude of the LIADI.

\begin{tabular}{ccc}
\hline $\begin{array}{c}\text { Out-of-balance } \\
\text { voltage in } \mu \mathrm{V}\end{array}$ & LIADI output $\Delta V$ in $\mu \mathrm{V}$ & $\begin{array}{c}\text { Relative reading } \\
\text { deviation } \boldsymbol{\gamma} \text { in } \%\end{array}$ \\
\hline 10 & Maximum amplitude & \\
20 & 10.2 & 2.0 \\
30 & 20.3 & 1.5 \\
40 & 30.6 & 2.0 \\
50 & 40.7 & 1.8 \\
10 & 51.1 & 2.2 \\
20 & Minimum amplitude & 1.0 \\
30 & 10.1 & 1.0 \\
40 & 20.2 & 1.3 \\
50 & 30.4 & 2.0 \\
\hline
\end{tabular}

\subsection{LIADI frequency range}

The frequency range of the compared voltages was defined according to the scheme in Figure 14. Again, the $\mathrm{CH} 0$ output of the calibrator supplied a voltage of $10 \sqrt{2} \mathrm{~V}$ with a frequency of $1 \mathrm{kHz}$. The same signal was applied to the second DI-3m IVD2 with a ratio of 0.500000 . The IVD1 ratio of outputs 1 and 2 was set to 0.100000 and 0.100005 , respectively, to compare the voltage amplitude of about $1 \sqrt{ } 2 \mathrm{~V}$. The $\Delta V$ values were measured at the LIADI resolution of $100 \mathrm{nV}$ for ten different frequencies (Table 5).

The relative frequency deviation of the LIADI readings was calculated accordingly:

$\gamma_{f}=\frac{\left(\Delta V_{f(1)}-\Delta V_{f}\right)}{\Delta V_{f(1)}} \cdot 100$,

where $\Delta V_{f(1)}$ and $\Delta V_{f}$ are IVD out-of-balance voltages at frequencies of $1 \mathrm{kHz}$ and $f, V$.

Next, we set the IVD1 ratio of outputs 1 and 2 to 0.001000 and 0.001005 , respectively, to compare the voltage amplitude of about $0.01 \sqrt{ } 2 \mathrm{~V}$. The measurements were repeated.

The results of the frequency range measurements are given in Table 5.

The measurements show that for all of the frequency range of 0.02 to $100 \mathrm{kHz}$, the relative error of comparison is less than $5 \%$ (Table 5).

\subsection{LIADI common-mode rejection}

The common-mode rejection was defined according to the scheme in Figure 15. Again, the $\mathrm{CH} 0$ output of the calibrator supplied a voltage of $10 \sqrt{2} \mathrm{~V}$ with a frequency of $1 \mathrm{kHz}$. The same signal was applied to the DI- $3 \mathrm{~m}$ with a ratio of 0.500000 . The $\Delta V$ values were measured at the LIADI resolution of

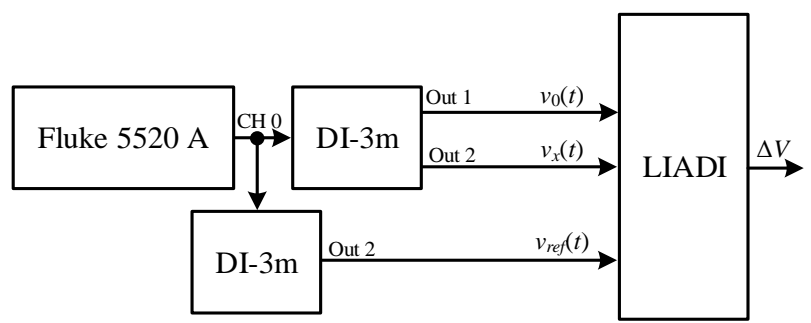

Figure 14. Diagram of the setup for measurement of the frequency range.
Table 5. Frequency range.

\begin{tabular}{|c|c|c|c|c|c|c|c|c|c|c|}
\hline \multicolumn{11}{|c|}{ A voltage comparison at voltage amplitude of $1 \sqrt{ } 2(\mathrm{~V})$} \\
\hline Frequency in $\mathbf{k H z}$ & 1 & 0.2 & 0.08 & 0.04 & 0.02 & 10 & 20 & 40 & 80 & 100 \\
\hline $\begin{array}{l}\text { IVD out-of-balance } \\
\text { voltage in } \mu \mathrm{V}\end{array}$ & 51.3 & 50.3 & 49.9 & 48.7 & 48.9 & 53 & 50.3 & 50 & 48.9 & 48.8 \\
\hline Error in \% & - & 1.9 & 2.7 & 5.0 & 4.7 & 3.3 & $1 . .9$ & 2.5 & 4.7 & 4.9 \\
\hline \multicolumn{11}{|c|}{ A voltage comparison at voltage amplitude of $0.01 \mathrm{~V} 2(\mathrm{~V})$} \\
\hline $\begin{array}{l}\text { IVD out-of-balance } \\
\text { voltage in } \mu \mathrm{V}\end{array}$ & 50.5 & 50.1 & 49.7 & 48.8 & 48.5 & 52.7 & 51 & 51 & 48 & 48.2 \\
\hline Error in \% & - & 0.8 & 1.6 & 3.4 & 4.0 & 4.3 & 1.0 & 1.0 & 4.9 & 4.5 \\
\hline
\end{tabular}

$10 \mathrm{nV}$ for 20 different frequencies (Table 6).

The common-mode rejection of the LIADI was calculated according to equation (6).

\section{CONCLUSION}

In this article, we have proposed a new scheme for a lock-in amplifier with a differential input, LIADI. The amplifier is based on two instrumentation amplifiers and a voltage follower and has a common-mode rejection that is better than $200 \mathrm{~dB}$ at

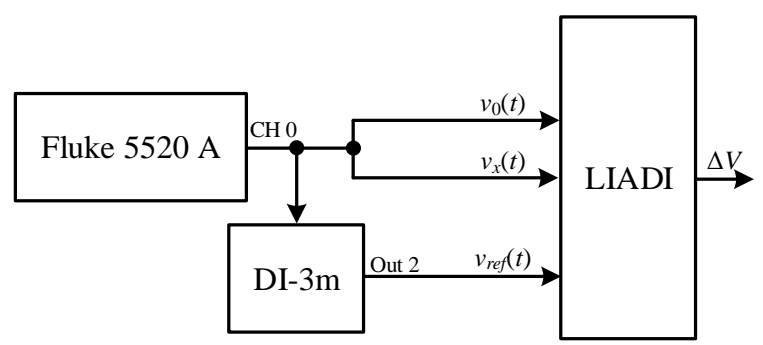

Figure 15. Diagram of the setup for measurement of the common-mode rejection ratio.

Table 6. Common-mode rejection ratio.

\begin{tabular}{|c|c|c|}
\hline Frequency in kHz & LIADI output $\Delta V$ in $n V$ & $C M R$ in $\mathrm{dB}$ \\
\hline 0.02 & $<10$ & $>200$ \\
\hline 0.04 & $<10$ & $>200$ \\
\hline 0.06 & $<10$ & $>200$ \\
\hline 0.08 & $<10$ & $>200$ \\
\hline 0.1 & $<10$ & $>200$ \\
\hline 0.2 & $<10$ & $>200$ \\
\hline 0.4 & $<10$ & $>200$ \\
\hline 0.6 & $<10$ & $>200$ \\
\hline 0.8 & $<10$ & $>200$ \\
\hline 1.0 & $<10$ & $>200$ \\
\hline 2 & $<10$ & $>200$ \\
\hline 4 & $<10$ & $>200$ \\
\hline 6 & $<10$ & $>200$ \\
\hline 8 & $<10$ & $>200$ \\
\hline 10 & $<10$ & $>200$ \\
\hline 20 & 10 & $>200$ \\
\hline 40 & 40 & $>180$ \\
\hline 60 & 90 & $>180$ \\
\hline 80 & 210 & $>160$ \\
\hline 100 & 820 & $>160$ \\
\hline
\end{tabular}


$1 \mathrm{kHz}$ and greater than $160 \mathrm{~dB}$ in the frequency range $20 \mathrm{~Hz}$ to $100 \mathrm{kHz}$. The amplifier has a high input impedance of $2000 \mathrm{MOhm}$ and $200 \mathrm{MOhm}$ for $V_{X}$ and $V_{0}$ inputs, respectively.

The new LIADI has the following characteristics:

- Frequency range: 0.02 to $100 \mathrm{kHz}$

- Input voltage range: $10 \sqrt{2} \mu \mathrm{V}$ to $10 \sqrt{ } 2 \mathrm{~V}$

- Voltage resolution: $10 \mathrm{nV}$ at a frequency of $1 \mathrm{kHz}$

- Resolution: $100 \mathrm{nV}, 1 \mu \mathrm{V}$ and $10 \mu \mathrm{V}$.

The developed LIADI is used to measure harmonics in planar fluxgate sensors. It is also used to calibrate the IVD ratio at Tomsk Polytechnical Univesity and at the All-Russian Scientific Research Institute of Physical and Radio Technical Measurements (VNIIFTRI, Moscow).

\section{ACKNOWLEDGMENT}

The research was carried out at Tomsk Polytechnic University within the framework of the Tomsk Polytechnic University Competitiveness Enhancement Program (grant \# VIU-INK 76/2017) and funded by the Russian Science Foundation (RSF) (Project \# 17-79-10083).

\section{REFERENCES}

[1] S. H. Tsao, Comparator for calibration of inductive voltage dividers, Proc. of the IEEE 55, 1967, pp. 708-709, DOI: https://doi.org/10.1109/PROC.1967.5651.

[2] N. M. Oldham, S. Avramov-Zamurovic, M. E. Parker, B. C. Waltrip, Low-voltage standards in the $10 \mathrm{~Hz}$ to $1 \mathrm{MHz}$ range, IEEE Trans. Instrum. Meas. 46 (1997), pp. 395-398, DOI: https://doi.org/10.1109/CPEM.1996.547354.

[3] L. Callegaro, V. D'Elia, A synchronized two-phase sinewave generator for AC metrology system compensations, IEEE Trans. Instrum. Meas. 49 (2000), pp. 320-324, DOI: https://doi.org/10.1109/19.843071.

[4] D. B. Kim, H. K. Lee, W.-S. Kim, An impedance bridge measuring the capacitance ratio in the high frequency range up to $1 \mathrm{MHz}$, Meas. Sci. Technol. 28 (2017), p. 025014, DOI: https://doi.org/10.1088/1361-6501/28/2/025014.

[5] T. Aoki, K. Yokoi, Capacitance scaling system, IEEE Trans. on Instrum. and Meas. 46 (1997), pp. 474-476, DOI: https://doi.org/10.1109/19.571889.

[6] R. A. Sedlacek, Wide-range Maxwell-Wien bridge utilizing inductive voltage dividers and precision electronic circuits, Proc of the Instrumentation and Measurement Technology Conference, Ottawa, Canada, 17 - 19 May 2005.

[7] H. Iida, A. Widarta, T. Kawakami, K. Komiyama, An accurate microwave attenuation measurement system using an inductive voltage divider based on a single-channel IF substitution method, Meas. Science and Techn. 17 (2006.), pp. 1947-1949.

[8] F. Delahaye, R. Goebel, Evaluation of the frequency dependence of the resistance and capacitance standards in the BIPM quadrature bridge, IEEE Trans. on Instrum. and Meas. 54 (2005), pp. 533-537.

[9] E. So, H.-G. Latzel, NRC-PTB intercomparison of voltage transformer calibration systems for high voltage at $60 \mathrm{~Hz}, 50 \mathrm{~Hz}$, and 16,66 Hz, IEEE Trans. on Instrum. and Meas. 50 (2001), pp. 419-421, DOI: https://doi.org/10.1109/19.918156.

[10] T. E. Lipe, Recent developments in the NIST AC-DC difference calibration service for thermal transfer standards, Proc. of the IEEE Systems Readiness Technology Conference, 2001, pp. 105-114,

DOI: https://doi.org/10.1109/autest.2001.948924.

[11] E. So, D. Angelo, T. Tsuchiyama, T. Tadokoro, B. C. Waltrip, T. L. Nelson, Intercomparison of calibration systems for AC shunts up to audio frequencies, IEEE Trans. on Instrum. and Meas 54 (2005),

DOI: https://10.1109/TIM.2004.843418.

[12] D. Corminboeufa, F. Overney, Inductive voltage divider calibration with sampling method, Proc. of the $16^{\text {th }}$ International Congress of Metrology, Paris, France, 7 - 10 October 2013, DOI: https://doi.org/10.1051/epiconf/20147700014.

[13] W. S. Sze, Comparator for calibration of inductive voltage dividers from 1 to $10 \mathrm{kHz}$, ISA Transactions 6 (1967), pp. 263 267.

[14] National Institute of Standards and Technology, Precision ratio measurements:

http://www.nist.gov/calibrations/precision-ratio.cfm\#54120 [Access date: 25.12.201]

[15] L. Callegaro, D. Serazio, Inductive voltage dividers comparison with a vector voltmeter, CPEM, Proc. of the Precision Electromagnetic Measurements Digest, Sydney, Australia, 14 - 19 May 2000, DOI: https://doi.org/10.1109/CPEM.2000.850956.

[16] S. Avramov, N. M. Oldham, D. G. Jarrett, B. C. Waltripm, Automatic inductive voltage divider bridge for operation from $10 \mathrm{~Hz}$ to $100 \mathrm{kHz}$, IEEE Trans. Instrum. Meas. 42 (1993), pp. 131-135,

DOI: https://doi.org/10.1109/19.278535.

[17] M. L. Meade, Lock-in Amplifiers: Principles and Applications, Peter Peregrinus, London, 1983, ISBN 9780906048948.

[18] C. Azzolini, A. Magnanini, M. Tonelli, G. Chiorboli, C. Morandi, A CMOS vector lock-in amplifier for sensor applications, Microelectronics J. 41 (2010), pp. 449-457, DOI: https://doi.org/10.1016/i.mejo.2009.11.002.

[19] F. A. Ghavanini, H. Rodjegard, P. Enoksson, An easy-toimplement method for evaluation of capacitive resonant sensors, J. Micromech. Microeng. 6 (2006), pp. 156-160, DOI: https://doi.org/10.1088/0960-1317/16/6/S23.

[20] P. Baranov, T. Nesterenko, E. Tsimbalist, S. Vtorushin, The stabilization system of primary oscillation for a micromechanical gyroscope, Meas. Sci. Technol. 28 (2017), p. 064004, DOI: https://doi.org/10.1088/1361-6501/aa66c6.

[21] L. Dong, W. Yin, W. Ma, S. Jia, A novel control system for automatically locking a diode laser frequency to a selected gas absorption line, Meas. Sci. Technol. 18 (2007), p. 1447, DOI: https://doi.org/10.1088/0957-0233/18/5/033.

[22] A. D'Amicob, A. De Marcellisa, C. Di Carloa, C. Di Nataleb, G. Ferria, E. Martinellib, R. Paolessec, V. Stornellia, Low-voltage low-power integrated analog lock-in amplifier for gas sensor applications, Sens. Actuator B-Chem. 144 (2010), pp. 400-406, DOI: https://doi.org/10.1016/j.snb.2009.01.045.

[23] S. Fu, A. Sakurai, L. Liu, F. Edman, T. Pullerits, V. Öwall, K. Karki, Generalized lock-in amplifier for precision measurement of high frequency signals, RSI 84 (2013), DOI: https://doi.org/10.1063/1.4827085.

[24] M. L. R. Barrios, E. H. Montero, J. Cé. G. Mancilla, E. P. Marínd, Application of lock-in amplifier on gear diagnosis measurement, 107 (2017), pp. 120-127, DOI: https://doi.org/10.1016/i.measurement.2017.05.015.

[25] A. Cifuentes, E. Marín, Implementation of a field programmable gate array-based lock-in amplifier, Measurement 69 (2015), pp. 31-41, doi: https://doi.org/10.1016/i.measurement.2015.02.037.

[26] M. Min, O. Märten, T. Parve, Lock-in measurement of bioimpedance variations, Measurement 27 (2000), pp. 21-28, DOI: https://doi.org/10.1016/S0263-2241(99)00048-2.

[27] P. F. Baranov, E. I. Tsimbalist, V. E. Baranova, Instrument for measurement of transfer function voltage dividers, Proc. of the Int. Siberian Conf. on Control and Communications, $21-23$ May 2015, Omsk, Russia, DOI: https://doi.org/10.1109/SIBCON.2015.7146992.

[28] V. L. Kim, D. S. Cheburenko, S. V. Merkulov, Programmable inductive voltage divider, Proc. of the $7^{\text {th }}$ Int. Forum on Strategic 
Technology, 18-21 Sept. 2012, Tomsk, Russia,

DOI: https://doi.org/10.1109/IFOST.2012.6357635.

[29] I. Budovskyn, T. Hagen, Precision AC-DC transfer measurement system based on a $1000-\mathrm{V}$ inductive voltage divider, IEEE Trans. Instrum. Meas. 58 (2009), pp. 844-847, DOI: https://doi.org/10.1109/TIM.2008.2011084.

[30] G. W. Small, I. F. Budovsky, A. M. Gibbes, J. R. Fiander, Precision three-stage $1000 \mathrm{~V} / 50 \mathrm{~Hz}$ inductive voltage divider, IEEE Trans. Instrum. Meas. 54 (2005), pp. 600-603,

DOI: https://doi.org/10.1109/TIM.2004.843377.

[31] Stanford Research Systems, Model SR830 DSP lock-in amplifier: User's Manual 2011:

http://www.thinksrs.com/downloads/PDFs/Manuals/SR830m. pdf [Access date: 25.12.2017].

[32] L. Callegaro, V. D'Elia, Guarded vector voltmeter for AC ratio standard calibration, IEEE Trans. Instrum. Meas. 51 (2002) pp. 632-635,

DOI: https://doi.org/10.1109/TIM.2002.802258.

[33] L. Callegaro, G. C. Bosco, V. D'Elia, D. Serazio, Direct-reading absolute calibration of AC voltage ratio standards, IEEE Trans.
Instrum. Meas. 52 (2003), pp. 380-383,

DOI: https://doi.org/10.1109/TIM.2003.810716.

[34] Texas Instruments, Inc., PGA207 high-speed programmable gain instrumentation amplifier: data sheet, 2013:

https://www.ti.com/lit/ds/symlink/pga207.pdf [Access date: 25.12.2017].

[35] P. Baranov, V. Borikov, E. Tsimbalist, B. B. Duc, Decrease uncertainty of measuring small differential signal against large common-mode signal, Proc. of the V International Forum for Young Scientists 'Space Engineering', 18-20 Apr. 2017, Tomsk, Russia, MATEC Web of Conf. 102, p. 01006,

DOI: https://dx.doi.org/10.1051/matecconf/201710201006.

[36] $10 \mathrm{MHz}$, Four-Quadrant Multiplier/Divider AD734: http://www.analog.com/media/en/technicaldocumentation/data-sheets/AD734.pdf, p. 12 [Access date: 25.12.2017).

[37] The USF Ultra-Stable Low TC Film Resistors 200 Series and 300 Series:

http://caddock.com/Online catalog/Mrktg_Lit/TypeUSF.pdf, p. 1 [Access date: 25.12.2017]. 